\title{
O avesso da nação: a recorrência de relações de trabalho escravo na fronteira amazônica no final do século xx e século xxi
}

\section{The reverse of the nation: the recurrence of slave labour relations on the Amazon frontier in the late 20th and 21 st centuries}

\author{
Vitale Joanoni Neto \\ Programa de Pós-Graduação em História \\ Universidade Federal de Mato Grosso, Brasil \\ vitalejneto@gmail.com \\ Regina Beatriz Guimarães Neto \\ Programa de Pós-Graduação em História \\ Universidade Federal de Pernambuco, Brasil \\ reginabeatrizg@gmail.com
}

\begin{abstract}
Resumo
O presente artigo visa tratar da recorrência de relações de trabalho degradantes, conhecidas no Brasil como Trabalho Análogo ao de Escravo ou Trabalho Escravo Contemporâneo, ao longo do século XX, com ênfase em sua presença na fronteira amazônica brasileira. Discutindo a permanência dessas relações de trabalho após o fím do escravismo, predominantemente entre os trabalhadores rurais, analisamos suas reconfigurações até o final do século quando os projetos de Integração da Amazônia foram desenvolvidos pelos governos militares, sob o pretexto de levar homens sem terra para terra sem homens, produzindo degradação ambiental à custa de mão de obra de migrantes, explorados e sem garantias de direitos.
\end{abstract}

Palavras-chave: Trabalho análogo ao de escravo; Amazônia; Desmatamento.

\begin{abstract}
This article aims to deal with the recurrence of degrading labour relations, known in Brazil as Work Analog to Slave or Contemporary Slave Labour, throughout the 20th century, with emphasis on its presence on the Brazilian Amazon frontier. Discussing the permanence of these labour relations after the end of slavery, predominantly among rural workers, we had analysed their reconfigurations until the end of the century when the military governments developed the Amazonian Integration projects under the pretext of taking men without land to land without men, producing environmental degradation at the expense of migrant workers, exploited and without guarantees of rights
\end{abstract}

Keywords: Work analogous to slave labour; Amazon; Deforestation

\section{INTRODUÇÃO}

A escravidão contemporânea é um fenômeno presente no mundo em que vivemos, denominação que ganha corpo a partir das últimas três décadas do século XX. Caracteriza-se por práticas de coerção em que pessoas são submetidas a condições degradantes e, muitas vezes, impedidas de se locomoverem e/ou de romperem com as condições de trabalho para as quais foram aliciadas, mesmo porque, quase sempre fazem parte de redes de tráfico. A escravidão contemporânea retira dos indivíduos a dignidade de pessoa humana, deste modo, atenta contra um 
direito básico consagrado pela Declaração Universal dos Direitos Humanos e pode assumir diferentes formas, desde o tráfico de mulheres para fins de exploração sexual ou escravidão por dívida até os casamentos forçados. Todas estas práticas são formalmente criticadas por governos e organizações internacionais, mas persistem. Uma das formas mais recorrentes deste tipo de subjugação da pessoa humana é o trabalho escravo contemporâneo ou "trabalho forçado" (denominação da Organização Internacional do Trabalho - OIT), que tem como referência, no Brasil, o Código Penal, artigo 1491 " “trabalho análogo a de escravo". Segundo o relatório da Walk Free Fundation (2018) “Índice Global de Escravidão”, cerca de 40,3 milhões de pessoas em todo o mundo são vitimadas por essas formas de exploração, a maioria mulheres (71\%) e mais da metade em condições de trabalho escravo (24,9 milhões de pessoas).

As narrativas dos casos de "escravidão contemporânea" estão fartamente documentadas pela literatura acadêmica internacional (LANDINGHAM, 1995; GOLDBERG, 1995; MERCER, 1981; LAKHDAR, 2013; LOPEZ-CORDOVA, 2013, CORREA DA SILVA, 2011; BALES, 2001/ 2016) e apresentadas em relatórios de organizações governamentais e não governamentais. É bom lembrar que a Declaração Universal dos Direitos Humanos foi aprovada por unanimidade pela Assembleia Geral da ONU e assinada em 1948 por 48 dos 56 países membros e os valores comuns nela expostos passaram a ser defendidos como princípios básicos "subjetivamente acolhidos pelo universo dos homens" (BOBBIO, 2004, p.28), em que os direitos humanos fundamentais estão relacionados à liberdade humana.

A convivência entre desiguais (cultural e étnica, religiosa e socioeconômica) gerou um inconformismo verbal, discursos que contestam o racismo, hoje muito comum nas redes sociais, e um conformismo prático (convivemos com a desigualdade social, racismo, homofobia, xenofobia). Uma sociedade que se retrata como moderna e uma modernidade que prescinde daqueles que a constroem forja condições que minimizam a precariedade para alguns grupos e maximizam a precariedade para muitos grupos sociais.

Contrariamente aos ideais da 'civilização', ou por causa deles, ao invés de criar um mundo cada vez mais aberto, escolhemos cruzá-lo com uma multiplicidade de fronteiras, não unicamente no sentido metafórico mas, e sobretudo, em seu sentido material. Não apenas por fronteiras nacionais (que hoje se tornam cada vez mais literais, materializadas assumindo a forma de muros), mas também por uma multiplicidade de fronteiras administrativas, territoriais e de limites virtuais que separam os ambientes em que vivemos, marcados por áreas opacas e limiares de distintos tipos. (SERJE, 2019, p11). São fronteiras que constroem territorialidades centrais e seus respectivos avessos, identificados como "periferia", nas quais o Estado atua delegando suas competências de

\footnotetext{
${ }^{1}$ Cf. a redação do Artigo 149, alterada pela Lei 10.803 de 11 de dezembro de 2003, em http://www.planalto.gov.br/ccivil_03/LEIS/2003/L10.803.htm
} 
governo para empresas privadas, igrejas, organizações não governamentais. Segundo Serje (2019, p20), ainda que tais espaços possam ser vistos como abandonados ou nas quais o Estado está indiferente, de fato as intervenções nessas fronteiras são o resultado de decisões tomadas nos centros metropolitanos, com linhas de atuação supreendentemente consistentes ao longo da história, pautadas pela lógica da destruição massiva, espaços onde as relações capitalistas se desenvolvem em condições de excepcionalidade e, portanto, onde as leis que regem as territorialidades centrais, não chegam. Essa condição de periferia viabiliza, torna possível a existência de relações de trabalho escravo, que conforme veremos abaixo, não desapareceram com o desenvolvimento e a modernização agrária.

Aqui reside o ponto central do estudo que oferece base a este texto, resultado de nossas pesquisas: a análise da presença do trabalho escravo na fronteira amazônica brasileira. Nossas pesquisas, privilegiam sua parte meridional localizada no território do estado de Mato Grosso. Entre 1970 e 2000, ela "se modernizou" sob as demandas econômicas do extrativismo, da criação de gado e do plantio de soja, estreitamente orientados pelo mercado internacional. E hoje, segundo Larsen, ela pode ser descrita como pós-frontier: "the host of new regulatory technologies, practices and institutions that nominally close, yet more accurately characterize and restructure, contemporary resource frontiers" (apud COY; KLINGLER; KOHLHEPP, 2017, p35). Uma espacialidade que entra o século XXI marcada pelo discurso da modernização e ainda assim, a escravidão tem sido ali presente ${ }^{2}$.

\section{A CONTIGÊNCIA HISTÓRICA DO TRABALHO ESCRAVO NO BRASIL}

A escravidão é um tema central no Brasil. O país conviveu com um regime legal escravista por aproximadamente 400 anos, como uma das faces, ou a principal face, do capitalismo mercantil imposto pelo poder metropolitano português. Os usos das palavras escravo e escravidão estão enraizados em séculos de domínio colonial e no Império brasileiro, no qual o comércio de pessoas para o trabalho duro nas lavouras, nos engenhos, nas minas de ouro e diamante, assim como, nas mais simples atividades domésticas, vigorou legalmente. Tais palavras guardam sentidos fortes em conceitos históricos e nas experiências contemporâneas, que caracterizam "um tipo de trabalho em que alguém está submetido a condições de vida tão violentas, que são indignas do ser humano.” (GOMES; GUIMARÃES NETO, 2018, p.12). Os registros de “trabalho escravo" são recorrentes na literatura brasileira e atravessam o século XX. Dadas as vicissitudes da construção do Estado no

\footnotetext{
${ }^{2}$ Em 2005, o Ministério do Trabalho e Emprego, libertou em Confresa, estado de Mato Grosso, Amazônia brasileira, 1.008 trabalhadores. Em 2019, este ainda é considerado o maior número de trabalhadores libertados em uma operação.
} 
Brasil, situações como as verificadas no campo brasileiro como o regime de colonato ${ }^{3}$ ou o trabalho do meeiro ${ }^{4}$, ou do parceleiro ${ }^{5}$, sujeitos às relações de compadrio ${ }^{6}$, para os quais a fixação em uma terra para morar e trabalhar era transformada em uma benesse do fazendeiro, estabelecia livremente os termos dessa "troca". Práticas que envolviam, muitas vezes, o trabalho do nascer ao pôr do sol e a apropriação de um percentual sobre o que o trabalhador produzia. Essas práticas contavam com a vigilância feita por jagunços ${ }^{7}$ e capatazes e no estabelecimento de regras de trabalho e permanência no local, que iam muito além dos aspectos profissionais (Cf. LEAL, 1975) e estavam naturalizadas tanto pelo trabalhador como pela sociedade local.

Dito isso, é importante distinguir o escravismo como uma instituição política legal da Colônia e do Estado brasileiro, entre os séculos XVI e XIX, e a outra forma de exploração de pessoas livres no século XX, sobretudo a partir da década de 1940 quando o Estado penaliza o que denomina de "condição análoga à de escravo" (código penal, artigo 149 do Decreto-Lei n.2848, de 7 de dez de 1940). O trabalho análogo ao de escravo no Brasil atinge majoritariamente homens adultos. Existem casos conhecidos e documentados sobre a exploração de mulheres e meninas para na prostituição no país (Cf. DIMENSTEIN, 1992), e do tráfico humano para o exterior (Cf. CORREA da SILVA, 2011). Contudo, nossa atenção e reflexão se concentram na exploração de homens adultos na área rural e em especial nas áreas de fronteira.

Nosso objetivo neste artigo é tratar da persistência de formas de trabalho análogas à de escravo na Amazônia brasileira. Encontramos descrições dessa forma de exploração de trabalhadores na região em vários momentos. Se na primeira metade do século XX acreditava-se que elas eram remanescentes do "atraso" que com a modernização desapareceriam, no final do

\footnotetext{
${ }^{3}$ Colonato, no contexto histórico brasileiro, refere-se ao processo de importação de mão de obra estrangeira, na segunda metade do século XIX, decorrente da crise do emprego da mão de obra escrava, em finais do sistema escravista. Alguns estados, especialmente São Paulo, começaram a trazer imigrantes europeus para trabalhar nas grandes fazendas de café. As famílias imigrantes assinavam um contrato onde recebiam um adiantamento e, em troca, concordavam em cuidar de um determinado número de pés de café. Porém, ao fim do contrato, os colonos, que recebiam um pagamento mínimo, teriam de pagar juros sobre o adiantamento, gerando uma dívida que os prendiam às fazendas.

${ }^{4}$ Meeiro é o agricultor que trabalha em terras que pertencem a outra pessoa. Em geral o meeiro ocupa-se de todo o trabalho e reparte com o dono da terra o resultado da produção. $\mathrm{O}$ dono da terra fornece o terreno, a casa e, às vezes, um pequeno lote para o cultivo particular do agricultor e de sua família. No Brasil, a agricultura de meação ainda é muito praticada, principalmente nas regiões com grande concentração fundiária e produção extensiva.

${ }_{5}^{5}$ Parceleiro é o agricultor que adquiriu lotes ou parcelas em áreas destinadas a Reforma Agrária ou à colonização pública ou particular. Os lotes de colonização são chamados Parcelas, quando destinados ao trabalho agrícola do parceleiro e de sua família. Há, ainda, o parceleiro tradicional que obtinha o direito de explorar a lavoura de uma parcela de terra de uma propriedade determinada.

${ }^{6} \mathrm{O}$ compadrio é um mecanismo social pelo qual os indivíduos se transformam em parentes de outros através de um ritual católico. Essa relação de parentesco "espiritual", torna-se tão importante quanto os laços consanguíneos. Embora esse compadrio pareça ser calcado na reciprocidade, ele inclui, muitas vezes, direitos e obrigações morais que legitimam a hierarquia entre as partes. Podia também significar a busca de proteção social e instrumento de controle senhorial. Tais características acabaram por reforçar o componente de dominação/submissão e ajudaram a debilitar o caráter igualitário que o parentesco espiritual pressupunha, contribuindo para a reprodução da hierarquia social. (LEAL, 1975)

${ }^{7}$ Jagunço ou capanga é o nome que se dá, em diferentes regiões do país, ao indivíduo que se prestava ao trabalho armado de proteção e segurança às lideranças políticas. Também pode ser conhecido por "pistoleiro" ou "guacheba" e mesmo "jagunço".
} 
mesmo século, vimos surgir um fenômeno novo (ou renovado?), bastante adequado às políticas denominadas de integração nacional propagandeadas pelos governos militares, a partir de 1964 com o golpe, que atendiam aos interesses dos empresários que se deslocaram para as "terras sem homens" do Norte do país. É possível traçar relações entre a existência dessas formas de exploração dos trabalhadores e a degradação ambiental? É possível analisar esses casos encontrados nessa área de fronteira amazônica como um fenômeno novo? Sendo assim, o que o distinguiria como novo?

Por todo o território brasileiro, mesmo antes do final do regime escravista, ocorreram denúncias de "escravização" de pessoas constituídas legalmente como "livres". Um desses casos foi registrado no livro "Memórias de um colono no Brasil", escrito por Thomas Davatz, um suíço trazido para o Brasil para trabalhar como colono nas lavouras de café em São Paulo em 1855. Tratado como escravo, fugiu, voltou para a Europa e publicou a obra denunciando a opressão, os desmandos dos poderosos, as reações dos oprimidos. (DAVATZ, 1980).

Belisário Penna, médico sanitarista, realizou uma expedição pelo interior do Brasil para observar as condições de vida da população do país. Em seu relatório divulgado em 1916, afirmou: “em toda a zona onde se explora a maniçoba ${ }^{8}$ existe praticamente a escravidão (...) nas zonas onde a água é escassa, esta é vendida aos maniçobeiros; ao cabo de algum tempo, o empregado é devedor e está impossibilitado de sair enquanto não saldar a dívida, que só faz crescer (...) As autoridades (... procuram) o devedor fugido...” (apud GOMES e GUIMARÃES NETO, 2018, p.9).

O Cônego Jácomo Vicenzi viajou pelo Mato Grosso no começo do século XX e deixou registrado na obra "Paraíso Verde", em várias passagens, casos de escravização de pessoas livres. Em uma passagem de sua obra, falou sobre os trabalhadores de uma fazenda que, após uma derrota em confronto armado de um grupo oposicionista por forças governistas, “forão distribuídos entre os poderosos governistas, e caridosamente escravizados juntamente com os seus haveres." (VICENZI, 1922, p.114). Em outra passagem trata, em tom de denúncia, "uma verdadeira e immoral caçada de menores pobres, filhos de humildes operários", que "arrancando-se do lar doméstico e, até mesmo de collegios, ... para serviço de criadagem, em casa de potentados":

A tutela, que, segundo autores reinicolas e pátrios, só se dá aos de menor idade, que se acham privados de seus protectores naturaes, vae-se transformando, entre nós, em uma verdadeira escravidão disfarçada, pois, aos interessados sob qualquer pretexto, ou mesmo sem elle, basta-lhes apresentar uma denúncia mentirosa ao escrivão do districto, dizendo, por exemplo que fulano (ou fulana) é paupérrimo e tem tantos filhos que cria com difficuldade e zás uma informação ao juiz de orphãos, e, logo em seguida, um termo de tutela, que varia de preço, conforme o felizardo tutor, pois si elle é algum chefe político, tem-no até de graça. (VICENZI, 1922, p.125)

\footnotetext{
8 Árvore comum no Nordeste brasileiro da qual se extrai um tipo de látex, produto chamado de "borracha do Ceará". Descrição relativa ao estado do Piauí.
} 
Após 1930 o interventor nomeado por Vargas para o estado de Mato Grosso, Antônio Mena Gonçalves, enviou tropas policiais para algumas usinas canavieiras na região de Santo Antônio do Leverger e Barão de Melgaço para verificar a existência de trabalhadores escravizados. Aleixo (1995, p.189) menciona a existência de troncos para açoite, solitária, execuções no pátio da fazenda à guisa de exemplo. O mesmo se verificou no Pará com o interventor Magalhães Barata

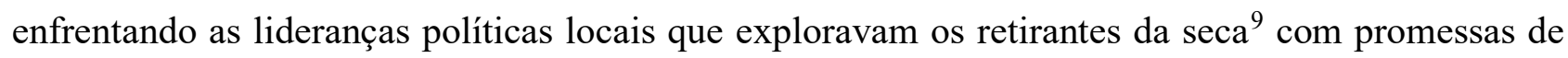
trabalhos, moradia e alimentação e no final os endividavam no chamado "sistema de barracão"10, também conhecido como de escravidão por dívida (Cf. CARNEIRO, 2018).

Segundo Martins (2009, p.130 e ss. e 2010, p.27 e ss.), a existência do fenômeno "trabalho escravo" no século XX se deveu ao modo como os trabalhadores rurais foram incorporados social e politicamente ao Estado Republicano. Ora por serem estrangeiros, ora por serem egressos da escravidão, pobres e desconsiderados como sujeitos portadores de direitos, esses trabalhadores não foram considerados cidadãos. A "Revolução de $1930^{11 "}$ criou o Ministério do Trabalho (26 de novembro de 1930), organizou a Consolidação das Leis do Trabalho (1943), e regulamentou como direitos as antigas reivindicações dos trabalhadores urbanos, mas deixou de fora os trabalhadores rurais, muito mais numerosos. Esse pacto entre a nova burguesia industrial e o velho latifúndio oligárquico vigorou durante todo o período getulista ${ }^{12}$, foi revitalizado na constituição de 1946 (MARTINS, 2009, p.132). Em 1963, no governo de Jango Goulart, pela Lei n.4.214 o governo promulgou o Estatuto do Trabalhador Rural, que tinha como objetivo "levar ao campo as conquistas trabalhistas". (GOMES, 2007)

Quando recorremos às fontes documentais sobre o período em que os trabalhadores rurais não tinham direitos sociais reconhecidos pelo Estado brasileiro, temos uma melhor ideia dos impactos da manutenção dessas relações de trabalho não regulamentadas, que desconsideravam os trabalhadores rurais e seus familiares como portadores de direitos (MONTENEGRO, 2003; BRAZIL, 1964). No Jornal Terra livre, ligado ao Partido Comunista Brasileiro, que circulou no país entre 1949 e 1964, percorremos as cerca de 70 edições entre os anos de 1954 e $1964^{13}$, buscando menções às denúncias feitas por trabalhadores acerca dessas relações de trabalho. Por 34 vezes a menção a trabalho forçado, escravidão, escravidão extrema, entre outras, sobre supressão de

\footnotetext{
${ }^{9}$ Retirante é o termo que se refere à pessoa ou grupo que abandona a sua terra por causa da seca (longos períodos sem chuva) e da miséria em busca de uma localidade que lhe dê melhores condições de vida. Foi amplamente usado no Brasil para se referir a nordestinos que migravam fugindo das secas. Cf. RIOS, K. S. A Utopia dos Pobres nas Narrativas de Migração no Ceará, Nordeste do Brasil. Trabalhos de Antropologia e Etnologia, v. 60, p. 179-190, 2020.

${ }^{10}$ Forma de exploração que obriga o trabalhador a comprar tudo o que precisa, desde alimentos e roupas, até as ferramentas necessárias para executar seu trabalho, da própria empresa, ou do empreiteiro, a preços muito elevados, o que provoca o seu endividamento.

${ }^{11}$ Revolução de 1930: movimento armado, liderado pelos estados de Minas Gerais, Paraíba e Rio Grande do Sul, que culminou com um golpe de Estado e pôs fim à Primeira República (1889-1929).

${ }^{12}$ Getúlio Vargas governou o Brasil como ditador entre 1930 e 1945 e como presidente eleito entre 1950 a 1954.

${ }^{13}$ O Jornal era mensal. Mas as dificuldades para sua elaboração e circulação (era entregue pelo correio e não vendido em bancas) e a condição de clandestinidade do partido explicam as lacunas nessa periodicidade.
} 
salários, ameaças por meio de "jagunços”, condições de trabalho e alojamentos precários, violências físicas, estão explícitas. Alguns exemplos das manchetes expostas: "100 jagunços de armas nas mãos vigiam 200 homens no trabalho escravo" (TERRA LIVRE, 1954, p.5), "Trabalho escravo e salário de fome na usina Santa Clotilde em Alagoas" (TERRA LIVRE, 1955, p.2). Em algumas matérias, a menção a conivência entre autoridades locais e fazendeiros, ou ao fato de a autoridade responsável pelo acolhimento de denúncias ser proprietário rural, também aparecem: “Tratados como escravo pelo deputado Augusto Figueiredo" (TERRA LIVRE, 1955, p.5).

Nossa intensão ao mencionar tais casos é demonstrar a afirmação acima de que a manutenção de uma economia agrícola fundada na produção de commodities (para usar um termo atual), voltadas para a exportação e, com frequência, com pouco valor agregado, baseada em grandes propriedades, altamente concentradas nas mãos de poucas empresas, não resultou no reconhecimento real dos direitos para os trabalhadores rurais. Tanto os egressos do escravismo, quanto os estrangeiros atraídos para o trabalho livre nas lavouras no Brasil no final do século XIX e início do século XX, passaram a compor um contingente de trabalhadores do campo, objetos de um aviltamento que é basicamente provocado por uma mudança legal (o fim do escravismo) e moral, o trabalho deixou de ser sinônimo de privação de liberdade para ser virtude (MARTINS, 2010, p.35).

Em meados do século XX, surgiu entre os trabalhadores rurais uma grande mobilização por direitos que avançou inclusive dentro do parlamento nacional por meio da Frente Parlamentar Nacionalista (1956 a 1964), levando para a esfera federal as reivindicações das Ligas Camponesas. (DELGADO, 2003, P.127). Elas estavam apoiadas na bandeira da reforma agrária. O Presidente da República, João Goulart, em março de 1964, tardiamente, incorporou as demandas das Ligas Camponesas naquilo que chamou "reformas de base", e no mesmo mês foi derrubado por um violento golpe de Estado impetrado por forças militares. Para Martins (2009, p.133), tais reivindicações drasticamente interrompidas com o golpe, teriam a capacidade para quebrar os "últimos grilhões que atavam e atam o Brasil aos processos mais imobilistas da tradição escravista, oligárquica e senhorial". O golpe, produto de um acordo político entre os grandes proprietários de capital e os grandes proprietários de terra, em articulação com os militares, promoveu o que se chamou de "modernização conservadora" (Cf. MOORE, 2002), interrompendo as tentativas de integração política dos trabalhadores rurais.

Tal como vimos, desde o início do século XX as notícias de exploração de trabalhadores "como escravos", ou de "escravidão branca", ou de trabalho forçado, aparecem registradas em diferentes locais pelo país. No Paraná, nas frentes agrícolas do café, nos anos 1950; no Nordeste, em estados como Pernambuco, Alagoas, nas usinas de açúcar e no plantio da cana; no sul de Mato Grosso, na colheita das folhas de erva-mate, entre os anos 1930 e 1940, para mencionar alguns. Com a chegada dos militares ao poder, em 1964, retomou-se um grande projeto nacional de 
“integração do país”, agora no contexto do auge da Guerra-Fria. Desde os anos 1950, Golbery do Couto e Silva escrevia sobre os riscos do que ele chamou de "vazio demográfico" no centro do continente, alertando para a necessidade de "inundar de civilização a Hiléia amazônica" (SILVA, 1981, p.92). O projeto não era novo, Getúlio Vargas em 1940 já havia iniciado a chamada "Marcha para o Oeste" e em seguida, por ocasião da assinatura dos Acordos de Washington, mais de 50 mil trabalhadores foram levados para a Amazônia brasileira. Chamados de Soldados da Borracha, acabaram por alimentar uma antiga rede de exploração de mão de obra para a extração do látex. Em 1955 quando assumiu a presidência, Juscelino Kubistchek deu início ao seu plano de governo, chamado "Plano de Metas". Uma dessas metas deu origem ao cruzeiro rodoviário que, em síntese, era uma rede de rodovias ligando Brasília, a nova capital, aos "quatro cantos" do país. Uma dessas rodovias, a BR-029 foi projetada para chegar a Rio Branco no Acre. A abertura dessas rodovias incorporou novas áreas do Centro-Oeste à esfera de controle da oligarquia rural brasileira (MOREIRA, 2003, p.155). As terras que se encontravam em poder de populações tradicionais e posseiros foram griladas ${ }^{14}$ e os pequenos produtores obrigados a abandoná-las, em alguns casos à custa de conflitos violentos, como os registrados em Trombas e Formoso (MOREIRA, 2003, p.1867).

O projeto político de “integração nacional”, legado por Vargas, foi implementado pelos militares em fins dos anos 1960 e mostrou-se melhor organizado que as iniciativas anteriores, tanto em suas justificativas ideológicas (SILVA, 1981; MATTOS, 1977; LIMA, 1971, p.14), quanto no arcabouço legal e administrativo criado e no aporte de recursos financeiros (ALMEIDA, 1992; GUIMARÃES NETO; JOANONI NETO, 2017, p.144). Novamente em sua execução considerou-se as áreas da Amazônia como "vazias", a floresta como um empecilho e os povos indígenas como incivilizados. Estender mais esse tema fugiria do proposto para este artigo, mas em síntese, nas palavras de Martins (2009, p.136), os governos militares ofereceram a Amazônia ao grande capital por meio de incentivos fiscais, atraindo um grande número de empresas do setor financeiro, industrial e de transporte, convertidas em proprietárias de terras. Foram estimuladas pela vultosa inversão de recursos governamentais, canalizados por financiamentos da Superintendência para o Desenvolvimento da Amazônia (SUDAM, criada em 1966), e aprovados pelo Instituto de Nacional de Colonização e Reforma Agrária (INCRA, criado em 1970). Parte substancial desse lastro financeiro provinha do Programa de Integração Nacional, (PIN, criado em 1970), com dinheiro captado do Banco Interamericano de Desenvolvimento - BID e da United States Agency for International Development - USAID a título de recursos para os investimentos em infraestrutura. Considerado um dos principais programas do Governo Federal para o desenvolvimento da

\footnotetext{
${ }^{14}$ No Brasil, grilagem de terras é a falsificação de documentos para, ilegalmente, tomar posse de terras. $\mathrm{O}$ agente de tal atividade é chamado grileiro.
} 
Amazônia, ele "contava com recursos de quatrocentos e trinta milhões de dólares, a serem constituídos nos exercícios de 1971 a 1974, com a finalidade específica de financiar o plano de obras de infraestrutura" (RESENDE, 1971, p.393). Outra razão para o desenvolvimento desse projeto estava nos conflitos pela terra no Nordeste, em face do legado político dos diversos movimentos sociais, particularmente, das Ligas Camponesas, que havia impregnado o movimento dos trabalhadores rurais em sua luta por direitos e foram violentamente reprimidos logo após o golpe militar. Contudo, a luta por melhores condições de trabalho mantinha as tensões provocadas pela concentração fundiária. No Sul do Brasil, por outro lado, constituía-se também um outro polo de conflitos no campo. Os grandes proprietários da agroindústria expropriavam e exploravam pequenos proprietários, meeiros e parceleiros, que se tornavam cada vez mais marginalizados da produção rural voltada para o mercado. A desagregação do trabalho familiar, com a fragmentação das propriedades, e o avanço da mecanização impediam que a pequena produção camponesa, que também não conseguia participar do sistema de crédito, com constantes endividamentos, pudesse competir neste mercado. Já aí predominava o estabelecimento do modelo agropecuário brasileiro (SILVA, 1984), fazendo com que os conflitos agrários se tornassem mais agudos, até mesmo envolvendo terras indígenas (SANTOS, 1993, p.55).

\section{OS DESLOCAMENTOS PARA A AMAZÔNIA E AS CONDIÇÕES PRECÁRIAS DOS TRABALHADORES}

Foi nesse cenário de precarização dos trabalhadores rurais do Sul e Sudeste do Brasil que centenas de milhares de famílias migraram para a Amazônia em busca de terras, entre 1970 e 2000, estimuladas pelas políticas governamentais e propostas das empresas privadas, interessadas na venda de terras. Atenderam às propagandas que promoveram as "novas terras na Amazônia" pelos denominados Projetos de Colonização (de fato, empreendimentos imobiliários). (CASTRO, 1994; GUIMARÃES NETO, 2002; JOANONI NETO, 2007; IANNI, 1979). Apenas para exemplificar, a população de Cuiabá, capital do estado de Mato Grosso, tinha em 1970, aproximadamente100 mil habitantes e chegou em 2000 a ter mais de 450 mil habitantes, segundo o Instituto Brasileiro de Geografia e Estatística (IBGE). O estado foi dividido pelo governo da ditadura militar, em 1977 (criou-se o estado de Mato Grosso do Sul), e no território remanescente, o de Mato Grosso, todo ele foi enquadrado na Amazônia Legal (Cf. Decreto-Lei no 291, de 28/02/1967). Surgiram, nesse período, pouco mais de 100 novos municípios, a maioria deles, sedes dos empreendimentos imobiliários estabelecidos pelos "Projetos de Colonização".

O movimento constante de displacement, replacement and misplacement (IORIS, 2017, p.212) implicou em práticas de controle, exclusão ou de cerceamento sobre de nativos e trabalhadores, visando impedir o pleno acesso à terra para plantio e às áreas de mata para coleta de 
madeira (lenha) ou frutas. Nas palavras de Rosa Luxemburgo, quando analisou as condições prévias indispensáveis ao processo de acumulação do capital, quanto à sua "elasticidade e capacidade súbita de ampliação", incluindo novos territórios que, graças à sua condição "pré-capitalista" veem ressurgir formas brutais de exploração da terra e do trabalho: "É somente o capital dotado dos respectivos meios técnicos que consegue executar a mágica de criar revoluções tão maravilhosas em tão curto tempo". (LUXEMBURGO1985, p.246).

A propaganda feita entre os pequenos produtores privilegiou o Sul do Brasil ${ }^{15}$, mas atraiu pessoas de todo o país interessadas nas novas frentes de trabalho, na esperança de possuir um pedaço de terra. O governo militar falava em "integrar para não entregar", as empresas falavam em terras férteis a bom preço, mas o que as famílias de agricultores encontraram foi o que Foweraker (1982, p.245) chamou de capitalismo autoritário. Neste quadro assiste-se a expropriação dos pequenos produtores que haviam vendido suas terras no Sul do país para "investirem nos projetos de colonização" privados (FOWERAKER, 1982, p.34; GOMES; GUIMARÃES NETO, 2018, p.129), e o rigoroso controle estatal, necessário para promover o modelo de desenvolvimento econômico traçado pelo projeto militar. Este contexto político e econômico implicou na manutenção dos trabalhadores rurais na sua condição de alijados dos direitos trabalhistas e políticos, ou na continuidade da reprodução de mecanismos de exploração atrasados e arcaicos de exploração do trabalho (MARTINS, 2009a, p.84) e acumulação do capital: sistema de barracão ou escravidão por dívida, trabalho degradante, jornadas exaustivas, cerceamento de liberdade.

\section{O TRABALHO ESCRAVO CONTEMPORÂNEO: PRECALIZAÇÃO E VULNERABILIDADE DOS TRABALHADORES}

Em 1971, Dom Pedro Casaldáliga divulgou a sua carta pastoral como Bispo da Prelazia de São Félix do Araguaia, e denunciou as empresas estabelecidas no nordeste do estado de Mato Grosso (indústrias de automóveis, bancos e aquelas ligadas ao setor de telecomunicações), que haviam adquirido grandes propriedades na região, cercando-as, desmatando-as com o fim de formação de pastagens para a pecuária bovina. Foi nesse contexto que expressões como "gato", "peão", "empreita"16 e "escravidão por dívida", entre outras ganharam novo sentido. No início dos anos 1970, nessa região, a mão de obra vinha em grande parte, do Nordeste brasileiro, os métodos de recrutamento eram as promessas de bom trabalho e remuneração justa, feitas geralmente por "gatos" que assumiam os trabalhos nas fazendas sob o regime de "empreita". Os trabalhadores

\footnotetext{
${ }^{15}$ Os lavradores do Sul do país, foram considerados “colonos ideais" (Guimarães Neto, 2002) por serem minimamente capitalizados, por possuírem pequenas propriedades nesse momento (década de 1970), muito valorizadas e que, vendidas, lhes possibilitariam comprar lotes nos projetos privados oferecidos na Amazônia.

${ }^{16}$ Gato: nome dado à pessoa que agencia a empreita. O intermediário entre o trabalhador e o proprietário. Peão: o trabalhador braçal. Empreita: trabalho a ser executado em um tempo determinado por um valor previamente combinado.
} 
aliciados, chamados “peões”, eram transportados até o local dos serviços e, uma vez lá, eram obrigados a pagar pelo transporte, ferramentas, alimentos que ficavam disponíveis no barracão da fazenda a preços exorbitantes; tinham que construir seus próprios barracos no meio da mata para não dormirem ao relento; sofriam com a altíssima incidência de malária e, ainda, pagavam pelo eventual uso de medicamentos. Existem muitos relatos de mortes de trabalhadores sem documentos, que eram sepultados como indigentes.

Os pagamentos eram efetuados como e quando o gato queria, muitas vezes apenas com vales ${ }^{17}$ que era uma maneira de prender o trabalhador e gerava um comércio paralelo desses papéis nos pequenos comércios da cidade, depreciando-os ainda mais. Inútil denunciar tais crimes à polícia militar, frequentemente conivente com as irregularidades, ou quando não, impotente para enfrentar os interesses dos fazendeiros da região (BALES, 2016, p.187). Ao fim dos trabalhos, os peões eram deixados nas vilas e tinham que arcar com as despesas de volta para suas cidades de origem. Muitos, envergonhados pelo insucesso da empreita, endividados e atingidos em seu orgulho (haviam saído de casa para ganhar algum dinheiro), não voltavam para suas famílias.

Eu to aqui há um ano e oito méis sem vê meu filho, minha mulher, minha filha, tá vivendo de favor (...) mas eu voltá pra lá desse jeito com o saco nas costa? Volto não (...) meu fillho tá com 15 anos [...] não. Depois que sai, não. É melhor não saí, fica em grupo ou (pausa) ...depois que sai e voltá com problema, não. (Depoimento de trabalhador no Centro de Pastoral para Migrantes. Cuiabá, 30 março 2007. Acervo do Núcleo de Pesquisa em História/IGHD/UFMT).

Vistos como um problema pelos moradores locais (pequenas cidades e vilas), muitos passaram a viver entre períodos de trabalho forçado nas fazendas (que podiam se estender por meses), e períodos de desemprego nas vilas à espera da próxima empreita, permanecendo em locais públicos (praças, ruas, terminal rodoviário), reconhecidos como de concentração desse tipo de trabalhadores e aos quais os "gatos" e proprietários de terra recorriam quando precisavam de sua mão-de-obra. Seu círculo social estava restrito aos "seus iguais", andarilhos, pedintes e prostitutas, todos considerados "gente da mesma classe" (MARTINS, 1998, p.706).

Así, si la violencia se ejerce contra sujetos irreales, desde el punto de vista de la violencia no hay ningún daño o negación posibles desde el momento en que se trata de vidas ya negadas. Pero dichas vidas tienen una extraña forma de mantenerse animadas, por lo que deben ser negadas una y otra vez. (BUTLER, 2009, p.60)

\footnotetext{
${ }^{17}$ O pagamento com vale: o trabalhador, ao final da empreita, recebia um papel, que podia ser uma folha de caderno, por exemplo, onde o gato descriminava um valor, datava e assinava (estamos falando de um universo pouco alfabetizado). O valor, descontado o que o trabalhador supostamente devia, era determinado pelo gato. Os comerciantes das vilas e cidades próximas, em comum acordo com o gato, aceitavam esses papeis como pagamento por compras, mas frequentemente cobravam um ágio para descontá-los. Dessa forma, o trabalhador era lesado pelo gato e novamente lesado pelos comerciantes locais.
} 
Neste enquadramento de "vidas perdidas ou negadas" e historicamente contingentes, inserem-se trabalhadores que não têm nenhum direito reconhecido e muito menos "vidas reconhecidas como vidas" (BUTLER, 2016). A Revista Realidade de março de 1972 trouxe em seu sumário: "Vendem-se escravos" e na página 112 o título da matéria era: "Comprei esse escravo. Nosso repórter foi a Barra do Garças (MT) e comprovou. A escravidão ainda existe". (CLEARI, 1972). Na reportagem, a equipe narra que foi a um pequeno hotel na referida cidade e escolheu três trabalhadores aleatoriamente, pagando suas dívidas, puderam levá-los dali. Essa era uma prática comum e facilmente encontrada na literatura sobre o trabalho nas áreas de fronteira na Amazônia brasileira (Cf. MARTINS, 2009a, p.71; ESTERCI, 2001, p.265; FIGUEIRA, 2004, p.174). O trabalhador endividado mesmo após ter realizado os trabalhos combinados, era deixado pelo empreiteiro, o gato, nesses hotéis ou pensões, chamados "peoneiros". Ali, ele podia dormir e comer precariamente, mesmo sem pagar por essa estadia que poderia durar semanas ou meses. Os empreiteiros, quando precisavam de mão-de-obra, recorriam a esses locais, pagavam pelas dívidas desses peões e podiam levá-los para nova empreita com esse valor já pesando sobre seus ombros. A isso se chamava "comprar a dívida" do peão. Em nenhum momento era perguntado ao trabalhador se ele desejava ou aceitava esse novo trabalho. O repórter pagou por um trabalhador de 32 anos, Cr\$153,00. O salário mínimo nesse ano era de Cr\$268,80. Fez isso apenas para provar que era possível. Nos dias em que ficou na pensão, conversando com os trabalhadores alojados, ouviu relatos de violências, ameaças, mortes. $\mathrm{O}$ que nos chamou a atenção, foi o fato dessa matéria ter sido veiculada em uma revista de circulação mensal, vendida em bancas em todo o país. O tom na reportagem, sem ser desrespeitoso, é o de curiosidade, mais do que denúncia, o que nos diz sobre como tais fatos eram socialmente vistos e aceitos, desde que na longínqua fronteira.

Durante a década de 1980, em outra área de expansão capitalista, noroeste do estado de Mato Grosso, outros casos também foram denunciados. Famílias inteiras foram trazidas do Paraná, atraídas por ofertas de terra e empregos, e submetidas às relações de trabalho degradantes e condições de vida indignas. Na região de Vilhena (RO), em 1983, organizações católicas como o Conselho Indigenista e Missionário, CIMI e a Comissão Pastoral da Terra (CPT), denunciaram casos de trabalho escravo (Cf. CIMI, 1988, p.56 e CPT, 1989, p.58). Nos relatos das pessoas atingidas é possível perceber o medo, o desconhecimento de direitos que, aliás, não faziam nenhum sentido para elas, além da vergonha diante de humilhações sofridas:

Foi gente daqui [...] que trabalhava, foi no Paraná busca gente [...] veio umas 18 famílias [...] trabalha em serraria [...] numa fazenda. Foi pra lá que nós viemo [...] eu vim contra a vontade e to aqui até hoje também [...] nós ia juntá dinheiro co rodo [...] meu Deus... até hoje nós não temo nada [...] tinha o mercado da firma nessa fazenda, então eles vendiam pra gente o preço que eles queriam [...] no pagamento, final do mês você ia lá não tinha nada porque você tava devendo tudo no mercado [...] entrou eu e minha irmã também trabalha pra ajuda o marido, pra vê se no final do mês nós tinha o que recebê na firma, mas 
chegava lá era zero engolindo zero e nós não tinha nada [...] era só o feijão, o arroz, que tinha, o sal e o açúcar [...] todo mundo comprava pouco pra ver se no final do mês tinha alguma coisa pra recebê [...] tinha leite na fazenda, mas eles não vendia pros empregado. As crianças queria tomar leite, não tinha jeito de dá porque eles não vendia [...] a minha casa [no Paraná] casa de pobre, mas eu tinha casa pra morá, era minha mesmo, tinha banheiro dentro de casa, tinha luz, água encanada, um quintal grande, era uma casa bonita, tinha três quartos, sala, cozinha, dispensa, área, era uma casa gostosa; onde o marido teve a ideia de botá tudo fora pra vim pra cá [...] o que me aconteceu de bom aqui [na cidade de Juina, na zona urbana] foi que eu não passei necessidade como eu passava, só isso mesmo, que outra coisa... [a pesquisadora perguntou: “quanto tempo ficaram na fazenda?"] cinco anos, sofremo até não quere mais...( Depoimento. Juina, 26 set. 2000. JOANONI NETO, 2007, p.73)

O que vemos no relato acima não é apenas o descumprimento de leis trabalhistas. Essas pessoas foram atingidas em sua dignidade e lesadas em seus direitos fundamentais. Chama-nos a atenção o tom não de indignação, mas de resignação na fala da pessoa entrevistada. Ela poderia se lamentar dos salários e direitos não recebidos, poderia bradar contra a injustiça de que foi vítima, mas sua memória remeteu à promessa de riqueza que iludiu o marido como uma ponte que leva à busca das razões da migração para o Mato Grosso, à dureza do cotidiano de trabalho na serraria, à dor da mãe em não poder atender ao desejo dos filhos de tomar leite. Seus sonhos remetem teimosamente ao passado, à casa que ainda é sua, pois é mantida em sua memória, preservada como algo caro, sinal de um tempo, talvez mitigado pela memória que ela apresenta a si própria, como um passado feliz. Esse relato trata de um caso de migração e de sujeição de toda uma família. A regra, ou os casos mais comumente encontrados, tratam da sujeição de homens adultos, já que o tipo de trabalho a ser executado, muito pesado, tem neles o foco privilegiado, ou dito de outra forma, os “custos" para a manutenção de uma criança, de uma mulher e de um homem são os mesmos (ainda que baixíssimos), mas a extração de excedentes nesses casos, se dá com melhor resultado nesses últimos.

Segundo o Jornal O Estado de São Paulo, em 1975 havia mais de 200 mil trabalhadores temporários ou volantes vivendo na fronteira amazônica "em condições de desespero" (apud FOWERAKER, 1982, p.90). Os Estados do Nordeste brasileiro foram grandes fornecedores dessa mão de obra (CPT/PI, 2004). As rodovias federais abertas na Amazônia Legal funcionaram como corredores migratórios. Em um levantamento feito entre estes trabalhadores no Piauí (CPT/PI, 2004), temos que 71\% tinham renda familiar de menos de 1 salário mínimo. 93\% dos que migravam eram homens; $51,7 \%$ eram analfabetos ou possuíam o primeiro nível do ensino fundamental; 90,8\% migravam para o trabalho temporário e apenas 23\% declararam ter saído uma única vez, entre 1999 e 2004, para esse trabalho. A grande motivação para a saída era a necessidade de dinheiro para sustentar a família $(43,3 \%)$, ou a falta de trabalho no local $(52,2 \%)$. Os destinos mais visados eram os Estados do Centro-Oeste (com boa parte na Amazônia meridional) (55,6\%) e as atividades realizadas estão em grande parte ligadas ao meio rural $(83,9 \%)$, sendo que a cana-de-açúcar, no 
caso desses trabalhadores era o que mais atraia (64\%). Um dado que chama a atenção é que 31,9\% dos entrevistados declararam migrar mediante o pagamento de um adiantamento do "gato", um forte indicador de aliciamento, primeiro passo para enredar o trabalhador na teia do trabalho análogo ao de escravo ${ }^{18}$. Sobre a atividade sucroalcooleira, ela se desenvolveu nessa fronteira nos mesmo moldes das frentes de trabalho já mencionadas e tanto no Pará quanto no Mato Grosso, as empresas destinadas às atividades pastoris e agrícolas, especialmente a exploração da cana de açúcar, foram campeãs, no século XXI, em números de trabalhadores resgatados pelas ações de fiscalização do Ministério do Trabalho e Emprego, como nos mostram os casos da Destilaria Gameleira (MT) com 1.008 trabalhadores resgatados em 2005 e a fazenda Pagrisa (Pará Pastoril e Agrícola S.A.) em 2007 com 1.064 trabalhadores resgatados ${ }^{19}$.

As fazendas formadas a pretexto de projetos agropecuários reduziram-se à pecuária extensiva. O processo de formação destas propriedades fazia uso da mão de obra dos peões, como já mencionado, para a derrubada da mata, a retirada de tocos e raízes, construção de cercas e plantio do capim. Todo o trabalho era basicamente manual, sem controle sobre jornadas ou acordos quanto ao recebimento de salários e, muito frequentemente, incidia no uso do trabalho análogo ao de escravo. Para Martins (2009a, p85), este tipo de exploração é uma variação extrema do trabalho assalariado e o que lhe dá origem e sentido é a precedência da composição orgânica do capital nos setores de ponta da economia. O uso do gato, como intermediário, a contratação de empreitas para a realização dessas tarefas é a reprodução em novo contexto de uma prática conhecida e que, nessa fronteira, atingiu "pessoas inexistentes", aqueles que nunca tiveram qualquer documento" (GOMES; GUIMARÃES NETO, 2018, p.79). O trabalhador foi coagido a trabalhar conforme as exigências do capital comercial, que lhe impôs uma remuneração decrescente e no limite, nula. Nesse contexto, se dão as complexas teias de relações sociais que reproduzem o cativeiro do trabalhador e que transformam a superexploração em trabalho análogo ao de escravo, pois é ali que se cria o endividamento que muitas vezes acompanha esse "peão", fazendo com que ele fique à mercê de um "mercado" perverso de vidas descartáveis. Nessa nova escravidão (MARTINS, 2009, 2009a; BALES, 2007, 2016; GOMES; GUIMARÃES NETO, 2018), o trabalhador pode ser comprado ou "contratado" em um botequim, em uma pensão, em um bolicho, ${ }^{20}$ em um bairro pobre da cidade de Barras - PI (FIGUEIRA, 2004, p.51), por exemplo, sem estranhamento ou juízos morais.

A criação da Comissão Pastoral da Terra (CPT), em 1975, as pressões nacionais e internacionais pelo reconhecimento da existência do trabalho escravo pelo Governo Brasileiro,

\footnotetext{
${ }^{18}$ Para mais dados sobre o tema, Cf. OIT, 2011; ONG Repórter Brasil e o Grupo de Pesquisa Trabalho Escravo Contemporâneo - GPTEC.

${ }^{19}$ Cf. mais sobre esse tema nos acervos do GPTEC e da Repórter Brasil.

${ }^{20}$ Pequena mercearia ou bar.
} 
culminaram em avanços na organização de um sistema repressivo ao uso deste tipo de trabalho. Registramos a entrada em operação dos Grupos Especiais Móveis de Fiscalização pelo Ministério do Trabalho e Emprego (1995), a extensão do direito ao Seguro Desemprego para os trabalhadores resgatados e a alteração pela lei 10.803 de 2003, do artigo 149 do Código Penal brasileiro, tipificando o crime de reduzir alguém a condição análoga ao de escravo, e afirmando que o bem jurídico protegido é a dignidade da pessoa humana (BRITO FILHO, 2014, p.63; BARROS, 2017, p.95). Somemos a essas ações institucionais e não institucionais, as campanhas preventivas realizadas pela sociedade civil organizada para levar a informação sobre direitos, alertando os trabalhadores sobre esse tipo de atividade; essas ações produziram mudanças, ou "adaptações" na prática deste crime. Longe de ter desaparecido, aqueles que empregam tais práticas no século XXI, nessas áreas aqui analisadas, fazem-no de modo mais "racionalizado", ou seja, os grupos de trabalhadores são levados para as frentes de trabalho por tempos curtos e evitam-se grandes empreitas ou grande número de trabalhadores. Essas táticas visam evitar fugas de trabalhadores, denúncias junto às organizações como CPT ou sindicatos de trabalhadores rurais, e ações fiscalizatórias com suas consequências.

Segundo Bales (2016, p.178), a oligarquia agrária no Brasil é chave para entendermos não apenas a escravidão, mas também a destruição ambiental. Em suas palavras, desenvolvimento agrário é frequentemente um eufemismo para destruição florestal e as batalhas contra esses males estão nos limites da corrupção, ganância e pobreza. Por trás de cada assassinato de trabalhador, de cada área de floresta destruída, de cada grupo de homens escravizados, esses elementos estão presentes. (BALES, 2016, p.180). Há uma forte correlação entre o trabalho análogo ao de escravo e o desmatamento na Amazônia. Elas coincidem em uma área correspondente a 42\% da floresta composta por terras devolutas (21\%) e sob disputas (21\%). (THÉRY, 2009, p.46). São áreas que pertencem à União e, portanto, deveriam fazer sua gestão, mas as alianças políticas, os conflitos de interesses, acabam por gerar um quadro de não governança sobre essas áreas, ou da presença do Estado delegada à empresas, igrejas, ONGs, o que favorece a exploração do trabalhador em condições análogas ao de escravo, entre outras violências.

Entre 1985 e 2016, 918 pessoas foram assassinadas na Amazônia e este número tem crescido de forma preocupante. Foram 29 vítimas em 2014, 50 em 2015 e 49 em 2016 (Global Witness, 2018). Em 2017 foram registradas 71 vítimas, um triste recorde. Em 2018 foram 24 assassinatos e outras 18 mortes até agosto de 2019. (CPT apud LUIZ, 2019). São, sobretudo, mortes em locais onde há conflitos pela posse da terra.

$\mathrm{Na}$ esfera federal, representantes do governo, pressionados pela opinião pública internacional, falam em preservação ambiental, enquanto na esfera local os representantes das oligarquias agrárias falam da geração de empregos e do crescimento econômico que virá se a 
floresta for cortada e a terra "melhor aproveitada". (BALES, 2016, p.187). Esse discurso que tem se reproduzido desde os anos 1960, nessa fase de investida do capital, levou o governo federal a destinar cerca de 6 bilhões de dólares/ano para a Amazônia Legal, mas os resultados para a população local, em termos de melhoria de sua qualidade de vida foram muito poucos e ruins. A Amazônia tem $61 \%$ do território nacional, $12 \%$ da população do Brasil e 6,5\% do PIB (PINTO, 2005, p.15). A floresta já tem pouco mais de $20 \%$ de sua área total desmatada (ALISSON, 2018), e está longe de se ver livre dos casos de exploração do trabalho análogo ao de escravo que continuam a ser encontrados lado a lado ao que há de mais moderno e tecnológico no agronegócio. (ROBERTO NETTO, 2018).

Ao final, esperamos ter demonstrado que falar da fronteira amazônica, de formas de exploração do trabalho análogas ao de escravo e do desmatamento é analisar temas convergentes. Seu pano de fundo é a expansão do capitalismo que produziu formas específicas de espacialidade que, por sua vez, produziram efeitos instrumentais e dispositivos políticos que articulam estrategicamente territórios e populações com os circuitos do capital. Podemos considerá-las como tecnologias espaciais pois são tanto operacionais como constitutivas de espacialidades do sistema mundial moderno. Produzem uma realidade espacial. (SERJE, 2019, p13). Assim, esse conjunto de tecnologias agrega-as inseparáveis umas das outras, e centrais para a produção de um espaço abstrato e global para a expansão e acumulação do capital em nome de um projeto civilizador.

O que permite a convergência desses elementos é o fato de que "A frontier is an edge of space and time: a zone of not yet - not yet mapped, "not yet" regulated. It is a zone of unmapping: even in its planning, a frontier is imagined as unplanned" (Tsing apud COY; KLINGLER; KOHLHEPP, 2017, p.29). No estado de Mato Grosso até o final dos anos 1980, foram vendidas mais de três milhões de hectares de terras em 85 empreendimentos imobiliários, operados por mais de 50 companhias privadas, norteadas para um modelo econômico de extração e orientadas para o mercado mundial. Os projetos de transporte e de infraestrutura foram as pontas de lança das políticas de reocupação territorial, por meio dos quais se buscou o acesso às terras, pessoas e recursos, para "integrá-los ao mundo moderno". Nessa fronteira se impôs o extrativismo como modelo de civilização e desenvolvimento e, assim, esses empresários, em nome do projeto civilizador, puderam vender o que não haviam comprado. (SERGE, 2019, p21) O estado de Mato Grosso está entre os recordistas em desmatamento florestal e entrou no século XXI com 9 milhões de hectares de soja plantados em 2015, 80\% da sua área cultivada. (COY; KLINGLER; KOHLHEPP, 2017, p.23).

Essa apropriação é inerente a relação dos centros metropolitanos com as fronteiras, marcadas por sua reinserção ao capitalismo, trazidas para o centro das atenções pois detém recursos vitais para o século XXI, como água, minérios, biodiversidade e oxigênio, orientadas para a 
demanda e os ritmos da produção para um mercado abstrato (SERGE, 2019, p21). A elas foi atribuído o papel de prover grandes fluxos de matérias primas e bens básicos (commodities) para o mercado global. Em muitos casos a extração de matérias primas se consegue com custos incrivelmente baixos, graças ao uso do trabalho análogo ao de escravo. Essas relações de exploração são possíveis, pois sobre essas áreas de fronteira vigora uma condição de excepcionalidade segundo a qual, o lícito e o ilícito, a regra e a exceção, convivem. Nesses territórios, “A tradição dos oprimidos nos ensina que o 'estado de exceção' em que vivemos é na verdade a regra geral." (BENJAMIN, 1985, p. 226).

Sobre essas áreas de fronteira vigora a suspensão da ordem e dos direitos comuns aos cidadãos nos centros metropolitanos. Uma condição excepcional que permite, entre outras coisas, a exploração do trabalho análogo ao de escravo. Nas palavras de Agamben "a exceção é uma espécie de exclusão" (2007, p25). Nesse texto, afirmamos a recorrência da submissão da pessoa à condição de escravo contemporâneo no Brasil, mas é importante destacar as diferenças inerentes à historicidade do fenômeno verificadas em fins do século XX, nessa fronteira brasileira. O amparo do Estado sob a ditadura militar (1964-1985) às forças econômicas estimuladas e interessadas em avançar sobre as terras da Amazônia, ampliando alternativas de investimento em um momento em que a economia nacional dava sinais de crescimento, se deu sob a forma de agências de Estado criadas para promoção de políticas e subsídios públicos. O uso das relações de trabalho análogas ao de escravo, foi um dos mecanismos usados para maximizar os ganhos dessas empresas, do desmatamento à construção do agrobusiness, epíteto da modernidade. Tais relações não são uma mera sobrevivência do passado, mas sim da expressão de uma virtualidade desse projeto modernizador que atinge áreas aparentemente insuspeitas (MARTINS, 2004, p.5), como a agroindústria.

Como parte do processo de abertura política, a posse de um governo civil (1985) e a promulgação da Constituição de 1988, fortaleceram-se as demandas pelos Direitos Humanos e o Estado brasileiro paulatinamente passou a reconhecer a existência do trabalho análogo ao de escravo. O Código Penal foi modificado (2003), o Ministério do Trabalho e Emprego assumiu ações de protagonismo no combate a esse crime nas áreas de fronteira (e não apenas nessas áreas) e o entendimento sobre o "trabalho escravo" mudou. Reduzir alguém à condição análoga a de escravo passou a ser tipificado como crime contra a dignidade humana. A categoria "trabalho análogo ao escravo", assumiu o sentido de uma metáfora (GEERTZ, 1989, p. 181), "na qual uma incongruência de sentido num nível produz um influxo de significado em outro". Em outras palavras, nominar o trabalhador de "escravo", quer justamente afirmar o que ele não é e que a existência de qualquer tipo de escravo ou escravidão é intolerável. Essa designação foi usada justamente por produzir uma operação de memória e essa é uma das razões do sucesso no seu uso, além de exprimir o fenômeno 
como "novo" (GOMES; GUIMARÃES NETO, 2018). Podemos pensar que na utilização específica dessa categoria, estão contidas forças diacrônicas sobre as quais não temos nenhum poder e que se expressam pela semântica. As mudanças nesse campo são muito mais lentas do que no campo do uso pragmático da língua. (KOSELLECK, 1992, p.134). A escravidão deixou marcas profundas em todos os aspectos da vida nacional brasileira. Constitui-se em um trauma que também é da ordem da memória, um passado que não termina de passar. Esse trauma precisa ser revivido, recontado, não por uma opção ou por decisão, mas por compulsão. (BUTLER, 2014, p.53). Entre esses trabalhadores no Brasil, "trabalhar como escravo" é uma forma de dizer sobre aquilo que "não deveria ser", soa como denúncia e implica em reivindicação de reconhecimento dos direitos humanos e de cidadania.

A demanda por direitos humanos está diretamente conectada ao Estado que detém a administração da justiça. A intensidade das mobilizações resultantes do processo de abertura política, a utopia da construção de uma sociedade igualitária, justa e democrática foi rapidamente cooptada e ressignificada, passando mesmo a legitimar práticas avessas aos direitos humanos (Cf. BUTLER, 2009, p. 60; SANTOS, 2013, p. 21). Consoante às práticas liberais e ao desenvolvimento neoliberal capitalista, a existência do trabalho análogo ao escravo passou a compor uma gramática despolitizada de transformação social, uma espécie de antipolítica. (SANTOS, 2013, p. 20).

\section{REFERÊNCIAS}

AGAMBEN, G. Homo Sacer. O poder soberano e a vida nua. Belo Horizonte: EdUFMG, 2007. $183 p$.

ALEIXO, L. H. G. Vozes no silêncio. Cuiabá: EdUFMT, 1995. 320p.

ALISSON, E. Desmatamento na Amazônia está prestes a assumir limite irreversível. FAPESP, fev. 2018. Disponível em: http://agencia.fapesp.br/desmatamento-na-amazonia-esta-prestes-aatingir-limite-irreversivel/27180/. Acesso em: 07 jan. 2019.

ALMEIDA, A. L. O. Colonização dirigida na Amazônia. (Série IPEA, 135). Rio de Janeiro: IPEA, 1992. 486p.

BALES, K. Gente descartável. A nova escravatura na economia global. Lisboa: Caminho, 2001. $338 \mathrm{p}$.

BALES, K. Blood and earth. Modern slavery, ecocide, and the secret to saving the world. New York: Spiegel \& Grau, 2016. 304p.

BARROS, M. D. Trabalho Escravo Contemporâneo. Rio de Janeiro: Multifoco, 2017. 137p.

BENJAMIN, W. Magia, técnica, arte e política. São Paulo: Brasiliense, 1985. 272p.

BOBBIO, N. A era dos direitos. Rio de Janeiro: Elsevier, 2004.96p. 
BRAZIL. The Troubled Land. Helen Rogers. USA: ABC, 1964. Disponível em: https://www.youtube.com/watch?v=jWq4898mg\&t=868s. Acesso em: 10 jan. 2019.

BRITO FILHO, J. C. M. Trabalho escravo: caracterização jurídica. São Paulo: LTR, 2014. 112p.

BUTLER, J. Quadros de guerra. Quando a vida é passível de luto. Rio de Janeiro: Civilização Brasileira, 2016. 288p.

BUTLER, J. Vida precaria. El poder del duelo y la violencia. Buenos Aires: Paidós, 2009. 194p.

BUTLER, J. ¿A quién le pertenece Kafka? Y otros ensayos. Santiago de Chile: Palinodia, 2014. $139 \mathrm{p}$.

CARnEIRO, A. J. D. Os castanhais do Sudeste do Pará: cotidianos e discursos (1930-1964). 2018. 328 f. Tese (Doutorado em História Social da Amazônia) - Universidade Federal do Pará, Belém, 2018.

CASALDÁliGA, P. Uma Igreja da Amazônia em conflito com o latifúndio e a marginalização social. São Félix do Araguaia: Mimeo, 1971.30p.

CASTro, S. P.; BARrozO, J. C.; COVEZZI, M. PRETI, O. A colonização oficial em Mato Grosso: A nata e a borra da sociedade. Cuiabá, EdUFMT, 1994. 290p.

CIMI. Amazônia e a investida do capital. In: América Latina 500 anos de conquista. São Paulo: Ícone editora, 1988.

CLEARI, O. Comprei este escravo. Revista Realidade, São Paulo, v. 7, n. 72, p. 112-118, 1972.

COMISSÃO PASTORAL DA TERRA. Conflitos no campo no Brasil. Goiânia: CPT, 1989. 252p.

CORRÊA DA SILVA, W. Forma contemporánea de esclavitud: trata de mujeres. $2011.470 \mathrm{f}$. Tese (Doctorado en Derecho Internacional y Relaciones Internacionales) - Facultad de Derecho, Departamento de Derecho Administrativo, Internacional Público Y Relaciones Internacionales, Universidad de Sevilla, Sevilla, 2011.

COUTO E SILVA. G. Conjuntura polícia nacional: o poder executivo \& geopolítica do Brasil. Rio de Janeiro: José Olympio, 1981. 310p.

COY, M.; KLINGLER, M.; KOHLHEPP, G. De frontier até pós-frontier: regiões pioneiras no Brasil dentro do processo de transformação espaço-temporal e sócio-ecológico. Confins, n. 30, p. 248, 2017.

CPT/PI; FETAG/PI; Pastoral do Migrante e DRT/PI. Campanha de prevenção ao trabalho escravo e combate ao aliciamento de trabalhadores no Piauí. Mimeo., [nov. 2004?].

DAVATZ, T. Memórias de um colono no Brasil. São Paulo: EDUSP/Itatiaia, 1980. 304p.

DELGADO, L. A. N. Partidos políticos e Frentes Parlamentares. Projetos, desafios e conflitos políticos na democracia. In: FERREIRA, J. e DELGADO, L.A.N. O tempo da experiência democrática. O Brasil Republicano. Rio de Janeiro: Civilização Brasileira, 2003.

DIMENSTEIN, G. Meninas da noite. São Paulo: Ática, 1992. 168p. 
ESTERCI, N. A ilusão do trabalho livre. In: ESTERCI, N.; FRY, P.; GOLDENBERG, M. (Org.). Fazendo antropologia no Brasil. Rio de Janeiro: DP\&A, 2001.

FIGUEIRA, R. R. Pisando fora da própria sombra. Rio de Janeiro: Civilização Brasileira, 2004. $448 \mathrm{p}$.

GEERTZ, C. A interpretação das culturas. Rio de Janeiro: Livros Técnicos Científicos, 1989. $224 p$.

GIRARDI, E. P. Atlas da questão agrária brasileira. Disponível em: http://www.atlasbrasilagrario.com.br/con_subcat/configuracao-territorial. Acesso em: 08 jan. 2019.

GLOBAL WITNESS. À que preço? Londres: Global Witness, 2018.

GOMES, A. M. C. Trabalho análogo a de escravo: construindo um problema. História Oral, v. 11, n. 1-2, p. 11-41, 2008.

GOMES, A. M.C.; GUIMARÃES NETO, R. B. Trabalho escravo contemporâneo: tempo presente e usos do passado. 1. ed. Rio de Janeiro: FGV Editora, 2018. 198p.

GPTEC. Grupo de Pesquisa Trabalho Escravo Contemporâneo. Disponível em: http://www.gptec.cfch.ufrj.br/. Acesso em: 07 jan. 2019.

Guimarães Neto, R. B. A lenda do ouro verde. Política de colonização no Brasil contemporâneo. UNICEN: Cuiabá, 2002. 168p.

GUIMARÃES NETO, R. B.; JOANONI NETO, V. A Amazônia e a política de Integração Nacional: o discurso da modernização entre o passado e o presente. Dialogos Latinoamericanos, v. 26, p. 144-156, 2017.

HOBSBAWM, E. Era dos extremos. São Paulo: Cia. das Letras, 1998. 632p.

IANNI, O. Colonização e contra-reforma agrária. Petrópolis: Vozes, 1979. 137p.

IORIS, A. A. R. Agricultural Frontiers as Controversial Place-making Territories. Dialogos Latinoamericanos, v. 26, p. 144-156, 2017.

JOANONI NETO, V. Fronteiras da Crença. Ocupação do Norte de Mato Grosso após 1970. Tanta Tinta/EdUFMT: Cuiabá, 2007.

KOSELLECK, R. Uma história dos conceitos: problemas teóricos e práticos. Estudos Históricos, Rio de Janeiro, v. 5, n. 10, p. 134-146, 1992.

LAKHDAR, S. O tráfico humano na França. In: FIGUEIRA, R. R.; PRADO, A. A.; GALVÃO, E. (Orgs.). Privação da liberdade ou atentado à dignidade: escravidão contemporânea. Rio de Janeiro: Mauad X, 2013.

LANDINGHAM, M. V.; SAENGTIENCHAI, C.; KNODEL, J.; PRAMUALRATANA, A. Friends, wives, and extramarital sex in Thailand. Bangkok: Chulalonghorn University, 1995.

LEAL, V. C. N. Coronelismo, enxada e voto. São Paulo: Alfa-Ômega, 1975. 180p. 
LIMA, A. A. A. A participação do Ministério do Interior no desenvolvimento e na ocupação da Amazônia. In: LIMA, A. A. A. Problemática da Amazônia. Rio de Janeiro, Biblioteca do Exército. 1971.

LÓPES-CÓRDOVA, D. La esclavitud contemporánea en la zona andina: un acercamiento bibliográfico. In: FIGUEIRA, R. R.; PRADO, A. A.; GALVÃO, E. (Orgs.). Privação da liberdade ou atentado à dignidade: escravidão contemporânea. Rio de Janeiro: Mauad X, 2013.

LUIZ, C. Até agosto Pastoral da Terra registra 18 assassinatos no campo. Destak Jornal. Disponível em: https://www.destakjornal.com.br/brasil/pelo-pais/detalhe/ate-agosto-cpt-registra-18assassinatos-no-campo. Acesso em: 12 dez. 2019.

LUXEMBURGO, R. A acumulação do Capital. São Paulo: Nova Cultural, 1985. 512p.

MARTINS, J. S. A vida privada nas áreas de expansão da sociedade brasileira. In: SCHWARCZ, L. M. História da vida privada no Brasil. São Paulo: Cia. das Letras, 1998.

MARTINS, J. S. Exclusão social e a nova desigualdade. São Paulo: Paulus, 2009. 140p.

MARTINS, J. S. Frentes de Expansão. Os novos espaços dos velhos problemas. Travessia, v. 17, n. 48, p. 5-8, 2004.

MARTINS, J. S. Fronteira. A degradação do outro nos confins do humano. São Paulo: Contexto, 2009a. 192p.

MARTINS, J. S. O cativeiro da terra. São Paulo: Contexto, 2010. 288p.

MATtOS, G. M. A geopolítica e as projeções do poder. Rio de Janeiro: José Olympio, 1977. $147 \mathrm{p}$.

MENEZES, E. P. Retalhos para a História de Rondônia. Manaus: IOEAM, 1980. 377p.

MERCER, J. Slavery in Mauritania today. London: Anti-Slavery International, 1981.

MONTENEGRO, A. T. Ligas Camponesas e sindicatos rurais em tempos de revolução. In FERREIRA, J.; DELGADO, L. A. N. O tempo da experiência democrática. O Brasil Republicano. Rio de Janeiro: Civilização Brasileira, 2003.

MOORE, B. Las orígenes sociales de la dictadura y de la democracia. Barcelona: Península, 2002. 864p.

MOORE, J. W. Capitalism in the web life. Ecology and the accumulation of Capital. London: Verso, 2015. 336p.

MOREIRA, V. M. L. Os anos JK: industrialização e modelo oligárquico de desenvolvimento rural. In: FERREIRA, J.; DELGADO, L. A. N. O tempo da experiência democrática. O Brasil Republicano vol.3. Rio de Janeiro: Civilização Brasileira, 2003.

OIT. Perfil dos principais atores envolvidos no trabalho escravo rural no Brasil. Brasília: OIT, 2011. 176p. 
OIT. Una alianza global contra el trabajo forzoso. Genebra: Oficina Internacional del Trabajo, 2005. 101p.

PINTO, L. F. Amazônia: perdida no rumo da história. In: COY, M.; KOHLHEPP, G. (Coord). Amazônia Sustentável. Desenvolvimento sustentável entre políticas públicas, estratégias inovadoras e experiências locais. Rio de Janeiro/Tübingen: Garamond/ Geographischen Instituts der Universität Tübingen, 2005.

REPORTER BRASIL. Disponível em: https://reporterbrasil.org.br/. Acesso em: 07 jan. 2019.

RESENDE, E. Estradas da Amazônia. In: LIMA, A. A. A. Problemática da Amazônia. Volume 90. Rio de Janeiro: Biblioteca do Exército, 1971.

RIOS, K. S. A Utopia dos Pobres nas Narrativas de Migração no Ceará, Nordeste do Brasil. Trabalhos de Antropologia e Etnologia, v. 60, p. 179-190, 2020.

ROBERTO NETTO, P. Tribunal condena fazendeiros por 222 'escravos' na Transamazônica. Estadão. São Paulo, 13 dez. 2018. Disponível em: https://politica.estadao.com.br/blogs/faustomacedo/tribunal-condena-fazendeiros-por-222-escravos-na-transamazonica/ Acesso em: 07 jan. 2019.

SANTOS, B. S. Se Deus fosse um ativista dos direitos humanos. São Paulo: Cortez, 2013. 190p.

SANTOS, J. V. T. Matuchos. Exclusão e luta: do Sul para a Amazônia. Petrópolis, Vozes, 1993. $282 \mathrm{p}$.

SERJE, M. El 'E/estado de frontera': las fronteras del capitalismo en América Latina. In: ROMANI, C.; MENEGAT, C.; ARANHA, B. (Orgs.). Fronteiras e Territorialidades. Miradas sul-americanas da Amazônia à Patagônia. São Paulo: Intermeios, 2019.

SILVA, S. Meninas dos olhos de Deus. Crianças escravas sexuais na Ásia. Goiânia: MCM, 2008.

THÉRY, H.; MELLO, N. A.; GIRARDI, E. P. e HATO, J. T. Atlas do trabalho escravo no Brasil. São Paulo: Amigos da Terra, 2009. 82p.

TERRA LIVRE. 100 jagunços de armas nas mãos vigiam 200 homens no trabalho escravo. Terra Livre, São Paulo, n. 47, p. 5, 1954.

TERRA LIVRE. Trabalho escravo e salário de fome na usina Santa Clotilde em Alagoas. Terra Livre, São Paulo, n. 52, p. 2, 1955.

TERRA LIVRE. Tratados como escravo pelo deputado Augusto Figueiredo. Terra Livre, São Paulo, n. 54, p. 5, 1955.

VICENZI, C. J. Paraíso Verde. Impressões de uma viagem a Matto Grosso em 1918. 1. ed. Cuiabá: Forgotten Books, 1922. 308p.

VIOLA, S. E. A. Direitos Humanos e democracia no Brasil. São Leopoldo: Ed. UNISINOS, 2008. 220p.

WALK FREE FUNDATION. Report 2018. Disponível em: https://www.walkfreefoundation.org/ Acesso em: 14 dez. 2018. 